Research Article

\title{
A Study on the Seepage Flow Characteristics and Disaster-Causing Mechanism of Collapse Column
}

\author{
Feisheng Feng $\mathbb{D}^{1,}{ }^{1,2}$ Suping Peng $\mathbb{D}^{1},{ }^{1}$ Pingjie Fu, ${ }^{1}$ Wenfeng Du, ${ }^{1}$ and Dongjing $X u^{1,3}$ \\ ${ }^{1}$ State Key Laboratory of Coal Resources and Safe Mining, China University of Mining \& Technology (Beijing), \\ Beijing 100083, China \\ ${ }^{2}$ State Key Laboratory of Water Resource Protection and Utilization in Coal Mining, Beijing 100083, China \\ ${ }^{3}$ Shandong University of Science and Technology, Qingdao, China \\ Correspondence should be addressed to Suping Peng; psp@cumtb.edu.cn
}

Received 13 May 2018; Revised 20 August 2018; Accepted 2 September 2018; Published 30 September 2018

Guest Editor: Qianbing Zhang

Copyright (c) 2018 Feisheng Feng et al. This is an open access article distributed under the Creative Commons Attribution License, which permits unrestricted use, distribution, and reproduction in any medium, provided the original work is properly cited.

\begin{abstract}
Factors such as the hydrogeological conditions, the lithological characteristics of the columns' components, and the lithological characteristics and stress conditions of the coal seam roof and floor are interrelated and jointly affect column collapse. In this study, the disaster-causing mechanism of column collapse was studied. Based on the system theory, a collapsed column is divided into the column and the surrounding fissure zone as two subsystems for analysis. And, the permeability coefficient of the broken rock under different conditions was measured by a self-designed equipment. The variations of the permeability coefficient for rock samples with different particle diameters, different axial pressures $P_{\mathrm{a}}$, and different seepage velocities were further studied. Through phenomena analysis and experimental data processing, it was concluded that, under the same pressure state, smaller particle diameter meant smaller permeability coefficient; with the increase of axial pressure, the permeability coefficient decreased; and the larger the water flow velocity was, the smaller the permeability coefficient became. For particle diameter $\Phi=2.5-5 \mathrm{~mm}$ or larger, the tiny particles formed by randomly washing and breaking in the water flow blocked some of the channels. For particle diameters smaller than $\Phi=2.5-5 \mathrm{~mm}$, the smaller permeability coefficient was attributed to the turbulence resulting from non-Darcy flow. The study on the permeability of the fractured rock mass clarified the mechanism of water inrush from the fissure zone of the collapsed column: the collapsed column itself was impermeable, and the permeability of the fissure zone around the collapsed column was related to the lithological characteristics of the rock within the fissure zone and the sequencing of rock strata. When mining coal in areas with collapsed columns, experiments on collapsed columns and fissure zones are prerequisites. This study has a certain referential value for coal mining in this region.
\end{abstract}

\section{Introduction}

According to incomplete statistics, from January 2001 to December 2017, there were a total of 182 water inrush accidents in China, resulting in 1807 deaths and 73 missing. During the four years from December 2013 to December 2017, there were 32 floor water inrush accidents (42.1\% of all water inrush accidents), causing 153 deaths ( $45.1 \%$ of deaths from water inrush accidents) [1]. Column collapse accounted for more than $90 \%$ of these accidents $[2,3]$. In developed coal-producing countries $[4,5]$, it is usually possible to locate coalfields in regions with simple hydrogeological conditions and adopt the method of open-pit mining or room [6] and pillar mining [7] to reduce or totally avoid the occurrence of such water hazards. However, for countries with relatively few coal resources, it is necessary to mine coal above the karst aquifer $[8,9]$. Karst collapsed columns are distributed in more than 20 coalfields in North China, as well as in the provinces of Shandong, Jiangsu, Shanxi, etc. [10] There are four main types of collapsed columns: conical collapsed columns, cylinder collapsed columns, leaning tower collapsed columns, and irregular collapsed columns $[11,12]$, as shown in Figure 1. Column collapse can destroy the coal seam and affect fully mechanized coal mining $[13,14]$, directly impairing the safety and efficiency of coal production. 


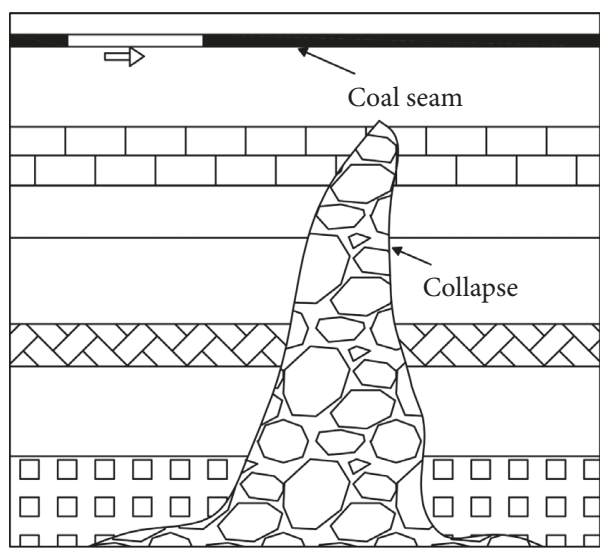

(a)

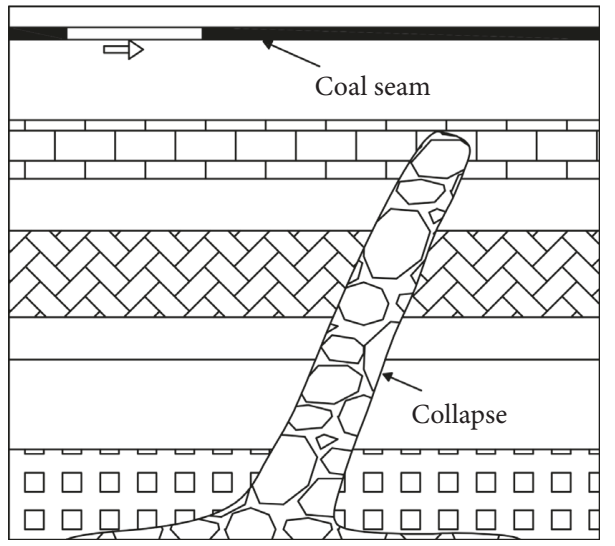

(c)

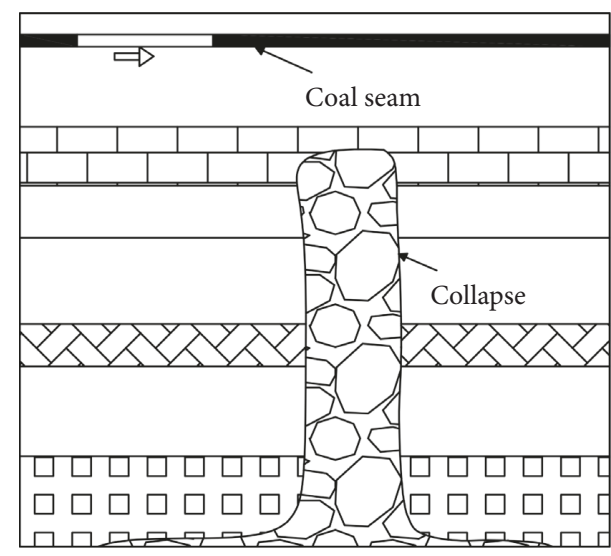

(b)

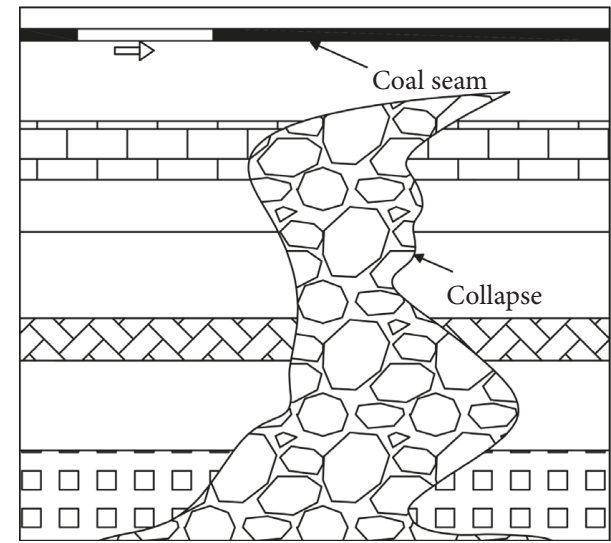

(d)

FIgURE 1: Four types of collapsed columns.

In recent years, scholars have conducted much research on water inrush from collapsed columns, and a systematic approach has gradually been formed. Qian [15] studied the discovery, nomenclature, distribution, and forms of collapsed columns in North China and proposed that collapsed columns were a product of gypsum karsts and explained their formation mechanisms in detail. Based on years of investigations, Yu et al. [16] designed their own system to test the permeability of cemented broken rocks and analyzed the impact of different factors on their water-resisting ability, providing a new perspective for research on the fissure zone of collapsed columns. Liu et al. [17] performed a numerical simulation with a plastic damage model based on seepage theory and studied the mechanism of water inrush from karst column collapse under confining pressure as a cascade disaster caused by geological and coupled hydromechanical factors. Zhang et al. [18] developed a physical test system for the seepage model of column collapse and formulated similar materials for fluid-solid coupling tests that can be used for permeability adjustment, providing new test materials, equipment, and related methods for the discovery of mining's influence on the seepage mechanism evolution of column collapse.

In the abovementioned studies, the connection between mining wall rocks and aquifers has been fully considered, but the structure and permeability characteristics of collapsed columns are ignored. The structure characteristics of rock are the basis for studying water inrush from the coal seam floor, and the abrupt change of the rock's permeability is an important piece of information for predicting water inrush in a coal mine. As a defect structure in the rock, the karst collapsed column is the main path through which the coal seam comes into contact with the underlying aquifer. In its affected zone, the rock cracks or becomes loose. In this study, we employ an experimental method to study the permeability characteristics of the floor rock, including the permeability characteristics of the intact coal seam floor, the collapsed columns, and the fissure zone around the collapsed columns and the permeability variation with confining pressure imposed on the rock samples. This provides the basic parameters for research on water inrush from column collapse under an intact coal seam floor.

\section{Materials and Methods}

2.1. Experimental Methods and Principles. In this study, with an MTS815.02 electrohydraulic servo rock mechanics system and the transient-state method, the stress-strain process and the permeability with changing ambient pressure for an intact rock sample were analyzed. The experiment mechanism is shown in Figure 2. Water pressure was simultaneously imposed on the top and bottom of the rock sample, and by reducing water pressure from the bottom, the initial pressure difference was 
obtained. The existence of fissures inside the rock sample led to the rapid attenuation of pressure difference; the control system recorded the signals of pressure difference, based on which the permeability $k$ of the rock sample was calculated. Due to the large permeability of the fracture medium, adoption of the transient-state method may result in the immediate disappearance of the pressure difference between the two ends of the rock sample or reduce it to a particularly small value. Therefore, the steady-state method was more appropriate for the experiment on a broken rock mass. The permeability apparatus for compacting broken rocks could provide axial pressure and allow water exchange, and based on the steady-state method, the stress-strain process and the permeability with changing ambient pressure for broken rocks of varied particle diameters were tested [19-21]. The experiment mechanism of the steady-state method is shown in Figure 3. The water pressure difference at both ends of the rock sample when seepage flow was in a stable state was recorded. The permeability coefficient was calculated based on the deformation formula of Darcy's law, as shown in Equation (1):

$$
K=\frac{Q L}{A\left(h_{1}-h_{2}\right)},
$$

where $Q$ is the amount of water flow, which can be obtained via the plunger velocity, $\mathrm{cm}^{3} / \mathrm{s} ; A$ is the cross-sectional area of the rock sample, $\mathrm{cm}^{2} ; L$ is the height of the rock sample, $\mathrm{cm}$; and $h_{1}-h_{2}$ is the water level difference of the rock sample.

2.2. Experiment Material. The samples were divided into three groups: the rock of the collapsed column, the rock of the fissure zone around the collapsed column, and the rock of the intact coal seam floor. The sampling sites were the X-187-08 collapsed column revealed by the track of the 10-108 working face of the Tuanbai Coal Mine of Huozhou Coal electricity Group Co. Ltd., the fissure zone around the collapsed column, and the intact coal seam floor $150 \mathrm{~m}$ in height above the collapsed column.

Considering that the degree of cementation and compaction at different strata of the collapsed column varies, the core of the collapsed column was divided into three sections: upper $(0-5 \mathrm{~m})$, middle $(5-10 \mathrm{~m})$, and lower (10-15 m). 5 samples were taken from each section, totaling 15 samples.

In testing the permeability of the broken rock, the rock sample was crushed into particles that were further classified into five groups based on their diameters: particle diameter 1 $(\Phi=15 \mathrm{~mm}-20 \mathrm{~mm})$, particle diameter $2(\Phi=10 \mathrm{~mm}-$ $15 \mathrm{~mm})$, particle diameter $3(\Phi=5 \mathrm{~mm}-10 \mathrm{~mm})$, particle diameter $4(\Phi=2.5 \mathrm{~mm}-5 \mathrm{~mm})$, and particle diameter 5 , representing the particle diameter of a broken rock mixture of the previous four types in the same mass ratio $(1: 1: 1: 1)$.

2.3. Experimental Apparatus. The stress-strain process and the permeability with changing ambient pressure for an intact rock sample were tested using the MTS815.02 electrohydraulic servo rock mechanics system. The ambient pressure was set as $p_{c}=4 \mathrm{MPa}$. The seepage flow was water with the following characteristics: mass density $\rho=1000 \mathrm{~kg} / \mathrm{m}^{3}$, kinematic viscosity $\mu=1.01 \times 10^{-3} \mathrm{~Pa} \cdot \mathrm{s}$,

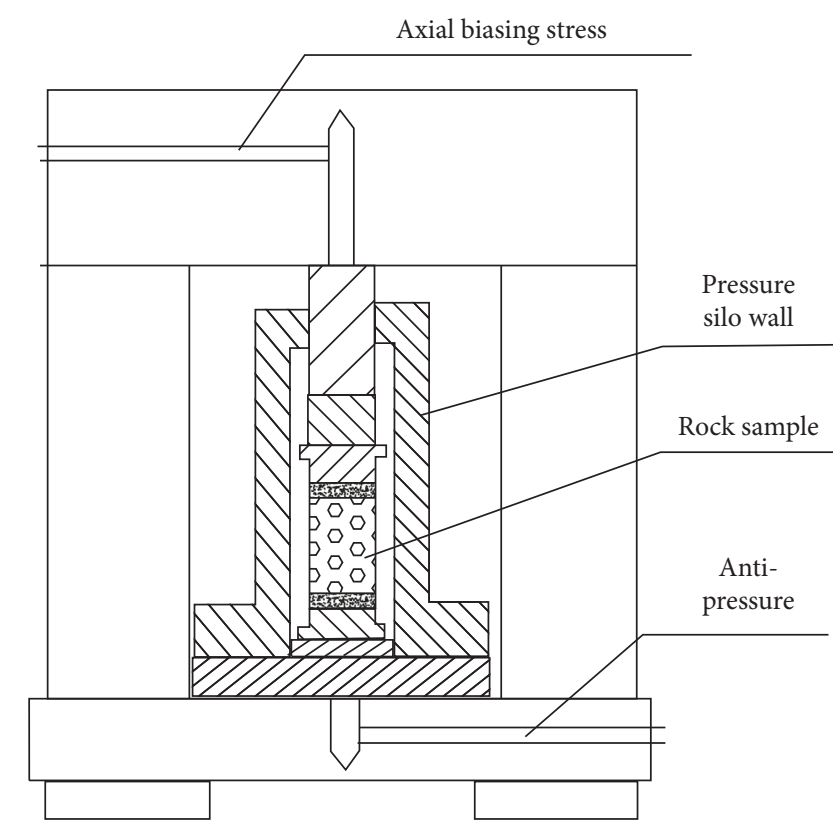

FIgURE 2: The experimental principles of the MTS815.02 electrohydraulic servo rock mechanics system.

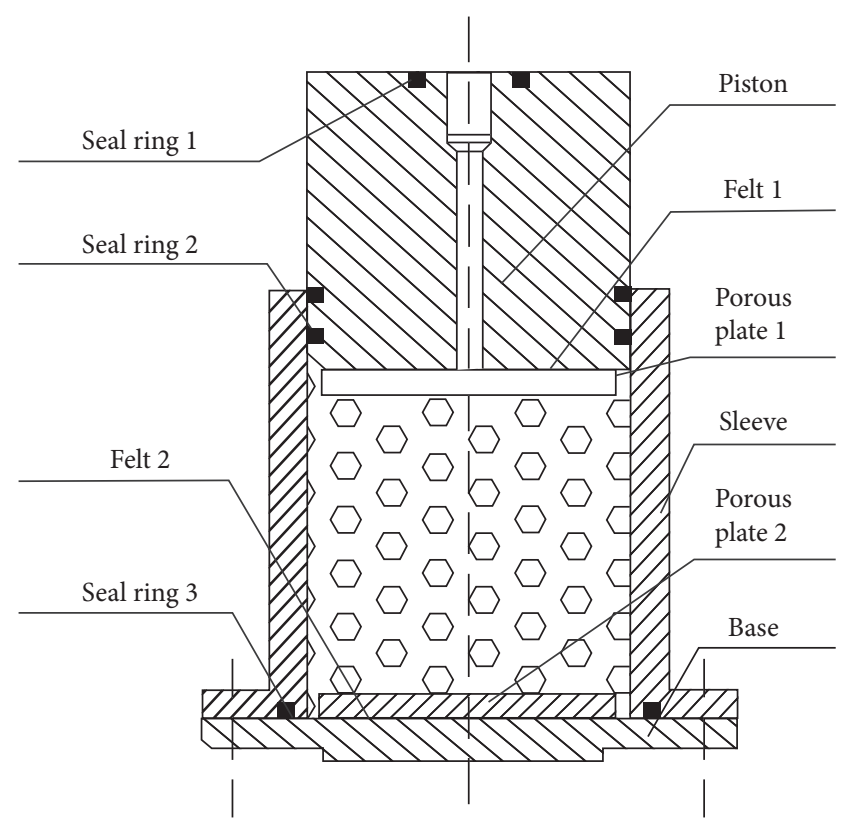

FIGURE 3: The permeability apparatus for compacting broken rocks.

compressibility $c_{f}=0.475 \times 10^{-9} \mathrm{~Pa}^{-1}$, and voltage stabilizer volume $B=0.332 \times 10^{-3} \mathrm{~m}^{3}$.

According to the time series of the pore pressure difference collected in the experiment, the permeability coefficient $K$ of the Darcy flow was calculated by Formula (1). The test work of the rock sample was accomplished with a permeability apparatus. Images of the rock sample and the permeability apparatus are shown in Figure 4. In the experiment, the loading process was controlled, and the axial loads were classified into 4 levels: $11 \mathrm{MPa}, 22 \mathrm{MPa}, 33 \mathrm{MPa}$, and $44 \mathrm{MPa}$; the corresponding velocities of the supercharger pistons for the axial 


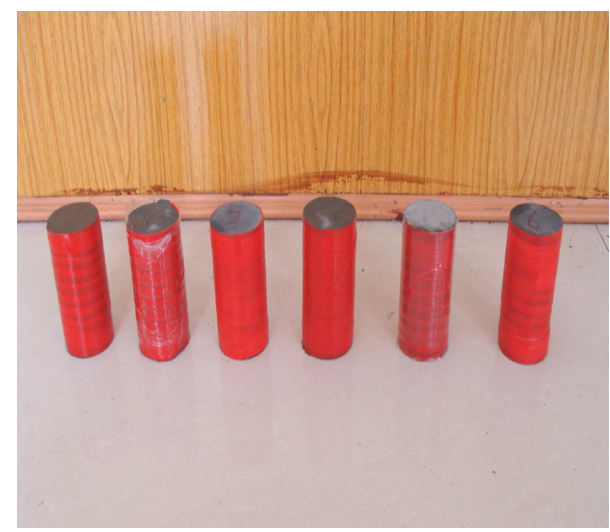

(a)

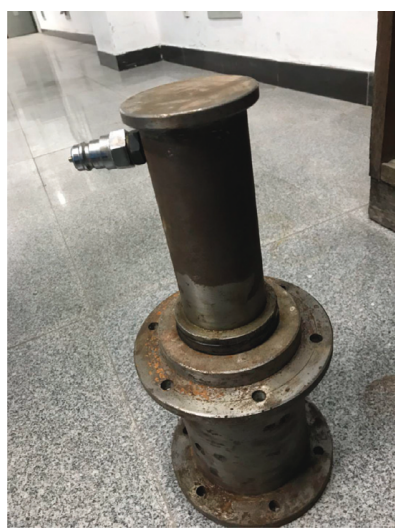

(b)

FIgURE 4: (a) Rock samples and (b) the experimental apparatus.

loads were $5.6 \times 10^{-5} \mathrm{~m} / \mathrm{s}, 11.2 \times 10^{-5} \mathrm{~m} / \mathrm{s}, 22.4 \times 10^{-5} \mathrm{~m} / \mathrm{s}$, and $33.6 \times 10^{-5} \mathrm{~m} / \mathrm{s}$, respectively.

\section{Results and Discussion}

The relationship between the strength and the permeability coefficient of the rock at three strata of the collapsed column with the strain is shown in Figure 5.

The data showed that the rock strength and permeability coefficient varied at the three sections of the collapsed column in a similar trend. In the early stage, the uniaxial compressive strength of the rock sample increased at nearly a constant speed, and after reaching $50 \mathrm{MPa}$, it decreased sharply. When it dropped to approximately $22 \mathrm{MPa}$, the decrease slowed down. The corresponding permeability coefficient of the rock sample began to increase when the strain reached approximately $9 \%$. It increased slowly in the early stage and surged to $(75-95) \times 10-12 \mathrm{~m} \cdot \mathrm{s}^{-1}$ when the strain reached $1.3 \%$; then, it drastically dropped to $15 \times 10^{-12} \mathrm{~m} \cdot \mathrm{s}^{-1}$ and basically remained unchanged. Rocks from three sections showed similar deformation rules, indicating that there was no significant difference among them. For strain from $0.3 \%$ to $0.9 \%$ ( $\mathrm{AB}$ segment), the axial pressures of rocks from the three sections gradually increased, and their permeability coefficients declined to a certain extent. At this stage, the original fissures in the rock were closed, and the gap between the specimen and the

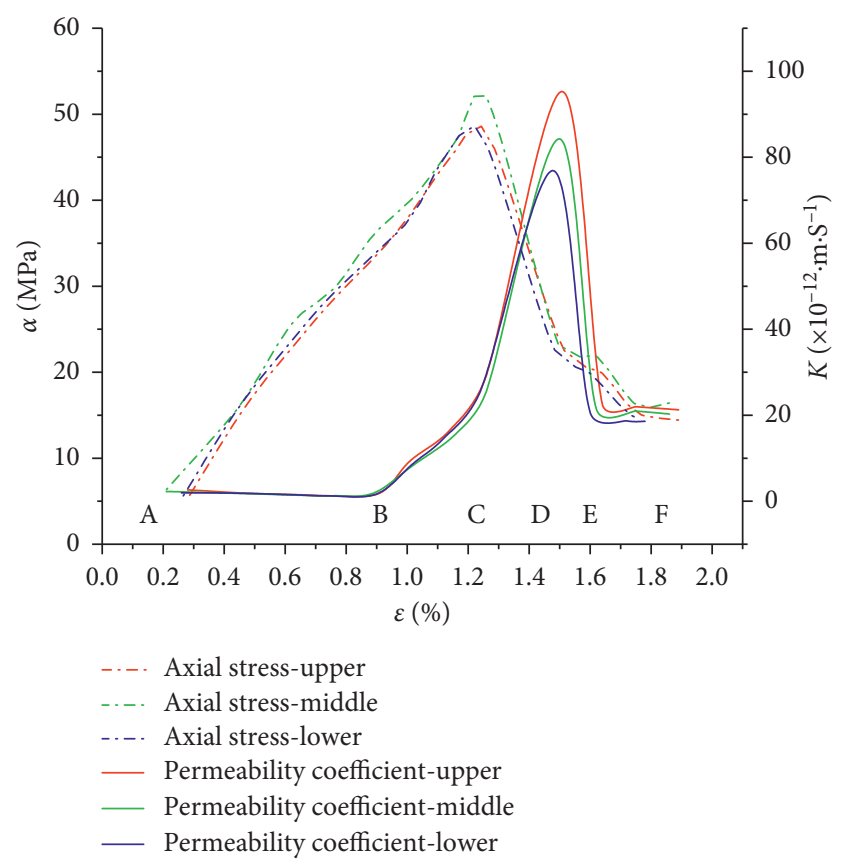

FIGURE 5: The changes for the rock strength and permeability coefficient with the strain of the collapsed column.

pressure plate was adjusted. For strain from $0.9 \%$ to $1.23 \%$ (BC segment), the axial pressure of rocks from the three sections gradually increased to an extreme value; the ultimate strength of rocks from the middle section was $53 \mathrm{MPa}$, slightly larger than the $47 \mathrm{MPa}$ of the upper and lower sections; the permeability coefficient of rocks from the three sections also increased gradually, and the increasing slope was not a definite value, indicating that it was a stage in which the original fissures were closed and a few new fissures came into being. For strain from $1.23 \%$ to $1.5 \%$ (CD segment), the axial pressure of rocks from the three sections decreased sharply with the increase of strain, and there was an obvious macroscopic structural failure plane forming on the rock; additionally, the permeability coefficient increased sharply, indicating that new fissures increased sharply within the rock. The extreme values of the permeability coefficients of rocks from the three sections were as follows: $95.41 \times 10^{-12} \mathrm{~m} / \mathrm{s}$ in the upper section $>82.72 \times 10^{-12} \mathrm{~m} / \mathrm{s}$ in the middle section $>76.85 \times 10^{-12} \mathrm{~m} / \mathrm{s}$ in the lower section, indicating that the permeability of the lower section was inferior to that of the upper section. The reason was that the lower section had better cementation and compaction; the result was consistent with the shape and structure of the collapsed column, and the three did not show significant differences because they were all of the same order of magnitude. For strain from $1.5 \%$ to $1.65 \%$ (DE segment), the axial pressure of rocks from the three sections decreased with the increase of strain, the rate of decline decreased, and the permeability coefficient decreased sharply and dramatically. For strain greater than $1.65 \%$ (EF segment), the axial pressure of rocks from the three sections decreased with the increase of strain, and the permeability coefficient was almost constant and tended to be a constant. The peak value of the permeability coefficient lagged behind the peak 
value of the rock strength. The reason was that, in the $\mathrm{BD}$ stage, the dislocation of the broken rock masses along the fracture plane and the climbing effect of the asperity body increased the gap in the macrofissures direction, and the permeability coefficient of the rock reached a peak. Subsequently, within the confining pressure limit, the intensifying deformation of the sample led to the compression and closure of the dislocation and the fissures, resulting in a sharp decrease in the permeability coefficient. The entire process was a process of fissure generation and closure.

With the same method, we analyzed the sandstone and mudstone from the fissure zone around the collapsed column and the intact coal seam floor to clearly show the trend of variation; the value of the mudstone's permeability coefficient was multiplied by $10^{3}$, as shown in Figures 6 and 7 .

The trend and principle of the axial pressure and permeability coefficient varying with the strain are similar to what have been discussed above. Experiments with samples from the fissure zone around the collapsed column and the intact coal seam floor mainly manifested the following aspects. The variation slope of the axial pressure of rock from the fissure zone was not stable, and the permeability coefficient showed a significant and relatively long-term decline at the initial stage of the experiment, indicating that there was a large number of nonuniform primary fissures within the rock [22-24].

In the final analysis, it is determined by the mineral composition, particle, pore, and fracture structure of its internal structure rock. The load on the rock sample, including pore pressure and confining pressure, is only an external condition that causes the microstructure of the rock sample to change. Due to the gray nature of the rock material structure, the rock permeability has a strong disorder. The permeability coefficient of the fissure zone was much larger than that of the intact complete floor. The experimental results and existing literature [25-27] all show that the key to research on the mechanism of water inrush from collapsed columns is the permeability coefficient of the broken rock. Table 1 lists the variations of the permeability coefficients of the broken sandstone and broken mudstone under different axial pressures $P_{\mathrm{a}}$, different seepage velocities, and different particle diameters $\phi$ of the rock samples.

Table 1 shows that the broken sandstone and broken mudstone had the minimum values of permeability coefficients, $0.11 \times 10^{-8} \mathrm{~m} \cdot \mathrm{s}^{-1}$ and $0.11 \times 10^{-10} \mathrm{~m} \cdot \mathrm{s}^{-1}$, respectively, when the gradation was $1: 1: 1: 1$, the pressure was $44 \mathrm{MPa}$, and the loading velocity was $6 v_{1}$; they had the maximum values, $154.76 \times 10^{-8} \mathrm{~m} \cdot \mathrm{s}^{-1}$ and $175.14 \times 10^{-10} \mathrm{~m} \cdot \mathrm{s}^{-1}$, respectively, when the particle diameter $\Phi$ was $15-20 \mathrm{~mm}$, the pressure was $11 \mathrm{MPa}$, and the loading velocity was $1 v_{1}$. With the increase of the water flow velocity, the permeability coefficients $K$ of the broken sandstone and broken mudstone decreased slightly. $\varphi$ was defined as the influence coefficient, i.e., the ratio between the difference of $1 v_{1}$ and $6 v_{1}$ and the permeability coefficients when $1 v_{1} \cdot \varphi=\left(K_{v_{1}}-K_{6 v_{1}}\right) /\left(K_{v_{1}}\right)$, and the influence coefficient obtained is shown in Figure 8.

The value of the influence coefficient mainly lies in the range of $0.1-0.95$ and was smaller than 0.6 in most cases. The influence coefficients of broken sandstone and broken

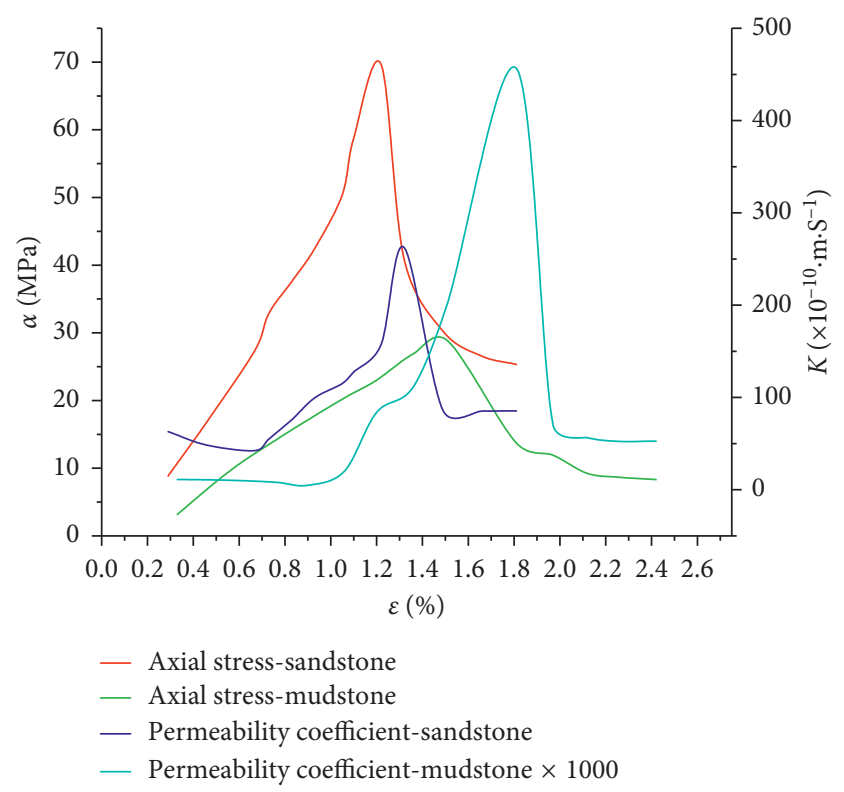

FIgURE 6: The relationship curve for the rock strength and permeability coefficient with the strain of the fissure zone.

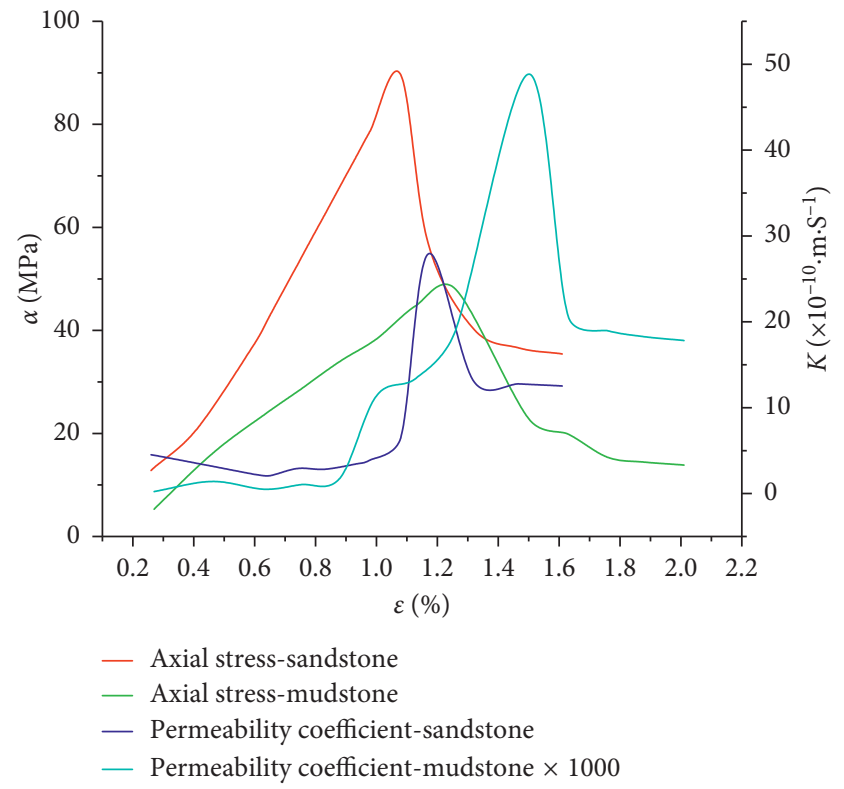

Figure 7: The relationship curve for the rock strength and permeability coefficient with the strain of the intact floor.

mudstone with particle diameter $\Phi=15-20 \mathrm{~mm}$ showed a synchronized changing trend with the increase of the water flow velocity. For particle diameter $\Phi=10-15 \mathrm{~mm}$, the influence coefficient of broken sandstone showed a slightly smoother changing trend than that of broken mudstone but still fluctuated explicitly. The influence coefficients of broken sandstone and broken mudstone with particle diameter $\Phi=10-15 \mathrm{~mm}$ and gradation $1: 1$ : $1: 1$ tended to stabilize and remain approximately 0.4 . The main reason was that, for particle diameter $\Phi=15-20 \mathrm{~mm}$, broken rocks were composed of large particles and formed many effective fissures, and thus the influence coefficient 
TABLE 1: Permeability coefficients of broken sandstone and broken mudstone $/ v_{1}=5.6 \times 10^{-5} \mathrm{~m} \cdot \mathrm{s}^{-1}$.

\begin{tabular}{|c|c|c|c|c|c|c|c|c|c|}
\hline \multirow{2}{*}{ Particle sizes and axial pressure } & & \multicolumn{4}{|c|}{ Broken sandstone $\left(\times 10^{-8} \mathrm{~m} \cdot \mathrm{s}^{-1}\right)$} & \multicolumn{4}{|c|}{ Broken mudstone $\left(\times 10^{-10} \mathrm{~m} \cdot \mathrm{s}^{-1}\right)$} \\
\hline & & $1 v_{1}$ & $2 v_{1}$ & $4 v_{1}$ & $6 v_{1}$ & $1 v_{1}$ & $2 v_{1}$ & $4 v_{1}$ & $6 v_{1}$ \\
\hline \multirow{4}{*}{$\Phi=15-20 \mathrm{~mm}$} & 11 & 154.76 & 151.66 & 149.52 & 137.34 & 175.14 & 157.15 & 154.86 & 126.26 \\
\hline & 22 & 121.25 & 116.71 & 117.13 & 41.98 & 34.92 & 48.06 & 33.15 & 29.85 \\
\hline & 33 & 69.56 & 23.27 & 12.45 & 3.33 & 14.04 & 17.67 & 16.86 & 3.17 \\
\hline & 44 & 1.37 & 1.06 & 0.73 & 0.51 & 2.95 & 2.05 & 2.55 & 1.45 \\
\hline \multirow{4}{*}{$\Phi=10-15 \mathrm{~mm}$} & 11 & 82.69 & 77.89 & 75.4 & 62.72 & 251.47 & 201.36 & 140.77 & 140.82 \\
\hline & 22 & 20.75 & 8.92 & 9.43 & 7.63 & 89.44 & 65.08 & 47.11 & 21.86 \\
\hline & 33 & 1.19 & 1.01 & 0.92 & 0.89 & 6.39 & 5.56 & 3.04 & 1.78 \\
\hline & 44 & 1.24 & 0.62 & 0.56 & 0.52 & 1.45 & 0.97 & 0.58 & 0.66 \\
\hline \multirow{4}{*}{$\Phi=5-10 \mathrm{~mm}$} & 11 & 44.32 & 40.78 & 35.12 & 30.63 & 52.84 & 42.7 & 36.37 & 29.92 \\
\hline & 22 & 15.6 & 7.12 & 6.98 & 5.3 & 25.12 & 23.92 & 19.12 & 12.84 \\
\hline & 33 & 1.08 & 0.87 & 0.68 & 0.54 & 9.7 & 8.67 & 7.89 & 5.3 \\
\hline & 44 & 0.79 & 0.54 & 0.51 & 0.48 & 2.07 & 1.77 & 1.25 & 1.23 \\
\hline \multirow{4}{*}{$\Phi=2.5-5 \mathrm{~mm}$} & 11 & 15.27 & 12.02 & 9.42 & 8.69 & 36.26 & 32.18 & 25.52 & 20.77 \\
\hline & 22 & 1.8 & 1.79 & 1.16 & 0.92 & 9.87 & 8.35 & 7.23 & 6.19 \\
\hline & 33 & 0.49 & 0.33 & 0.32 & 0.28 & 3.02 & 2.31 & 2.05 & 1.75 \\
\hline & 44 & 0.23 & 0.19 & 0.17 & 0.14 & 0.93 & 0.74 & 0.66 & 0.54 \\
\hline \multirow{4}{*}{ Mixture of different particle sizes: $1: 1: 1: 1$} & 11 & 7.04 & 5.76 & 4.72 & 3.24 & 16.05 & 13.47 & 10.85 & 7.72 \\
\hline & 22 & 1.42 & 1.29 & 1.09 & 0.84 & 6.48 & 5 & 4.13 & 3.87 \\
\hline & 33 & 0.37 & 0.31 & 0.28 & 0.24 & 2.12 & 1.78 & 1.55 & 0.98 \\
\hline & 44 & 0.17 & 0.15 & 0.14 & 0.11 & 0.55 & 0.43 & 0.33 & 0.29 \\
\hline
\end{tabular}

had larger values $[28,29]$. When the water flow velocity increased, the small particles resulting from the edge crush or particle break were randomly washed to fill in the fissures, blocking some of the channels, and therefore the influence coefficient at this stage had larger values and fluctuated in a wider range; when the particles composing the broken rock gradually decreased, the probability of such random filling and clogging of the fissures was reduced, so the influence coefficient generally had smaller values and showed small fluctuation $[30,31]$. When the particles composing the broken rock were much smaller or in a more balanced proportion (a mixture composed of various particles with different diameters in a mass ratio of $1: 1: 1: 1)$, the effective fissures within the rock sample were more uniform, and the value of the influence coefficient tended to be a constant. The possible reason for the existence of the influence coefficient was that laminar flow became turbulent with the increase of the water flow velocity, and the non-Darcy flow characteristics of the rock were more prominent. The influence coefficient was a constant consumption lessening the water flow velocity in the turbulent flow state $[32,33]$. The influence coefficient began to stabilize when the particle diameter $\Phi=2.5-5 \mathrm{~mm}$, which can be regarded as a critical value dividing Darcy flow and non-Darcy flow in this state.

In short, under the same conditions, the permeability coefficient of broken sandstone was nearly 1-2 orders of magnitude larger than that of broken mudstone. The permeability coefficient of broken sandstone was 1-2 orders of magnitude higher than that of intact sandstone. The permeability coefficient of broken mudstone was 2-3 orders of magnitude higher than that of intact mudstone. When the axial pressure imposed on the broken sandstone exceeded $22 \mathrm{MPa}$ and the axial pressure imposed on the broken

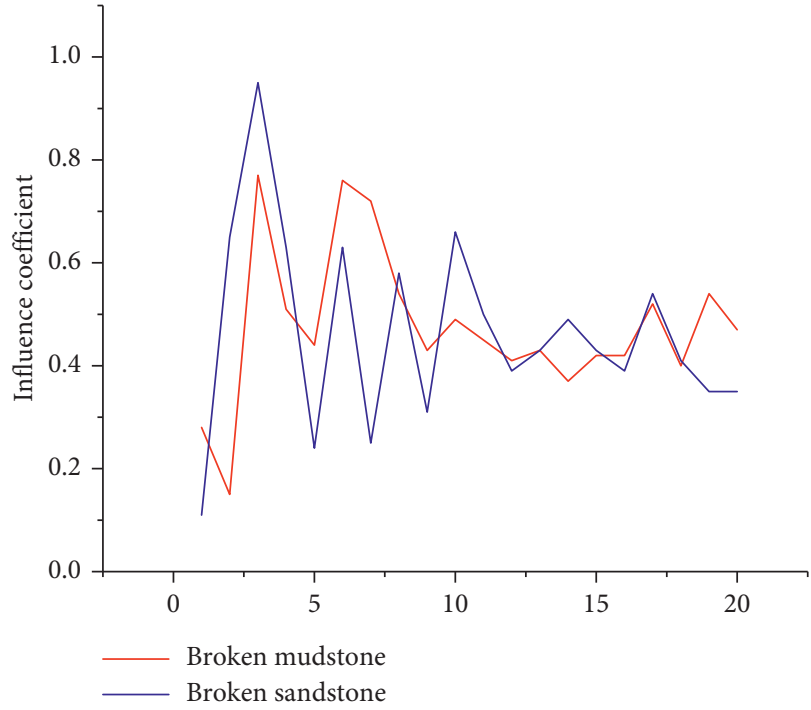

FIGURE 8: The influence coefficient curve of the broken sandstone and broken mudstone.

mudstone exceeded $11 \mathrm{MPa}$, their permeability coefficients were different than that of the intact rock of their own type, but they approximated or were smaller than the upper limit of the permeability coefficient of the aquifer. Considering the actual process of water inrush, the fissures were affected by different hydraulic pressures; after long-term continuous erosion and expansion, the water guiding channels were finally formed. Because the water inrush channels of the collapsed column were mainly composed of a series of fissures with the maximum permeability coefficient, the ultimate strength and permeability coefficient of various rocks were jointly analyzed, as shown in Table 2 .

The ultimate strength of the rock in the upper section of the collapsed column was $48.01 \mathrm{MPa}$, and the permeability 
TABLE 2: Maximum strength and permeability coefficient of each sample.

\begin{tabular}{|c|c|c|c|c|c|c|c|}
\hline & $\begin{array}{c}\text { Collapse } \\
\text { column-upper }\end{array}$ & $\begin{array}{c}\text { Collapse } \\
\text { column-middle }\end{array}$ & $\begin{array}{c}\text { Collapse } \\
\text { column-lower }\end{array}$ & $\begin{array}{c}\text { Fissure } \\
\text { zone-sandstone }\end{array}$ & $\begin{array}{c}\text { Fissure } \\
\text { zone-mudstone }\end{array}$ & $\begin{array}{c}\text { Intact } \\
\text { floor-sandstone }\end{array}$ & $\begin{array}{c}\text { Intact } \\
\text { floor-mudstone }\end{array}$ \\
\hline $\begin{array}{l}\text { Maximum axial } \\
\text { pressure }\end{array}$ & 48.01 & 52.01 & 48.01 & 69.63 & 28.81 & 89.63 & 48.01 \\
\hline $\begin{array}{l}\text { Maximum } \\
\text { permeability } \\
\text { coefficient }\end{array}$ & 0.95 & 0.84 & 0.77 & 262.39 & 0.47 & 27.9 & 4.9 \\
\hline
\end{tabular}

coefficient was $0.95 \times 10^{-10}$; the ultimate strength of the rock in the middle section of the collapsed column was $52.01 \mathrm{MPa}$, and the permeability coefficient was $0.84 \times 10^{-10}$; the ultimate strength of the rock in the lower section of the collapsed column was $48.01 \mathrm{MPa}$, and the permeability coefficient was $0.77 \times 10^{-10}$; the ultimate strength of the sandstone in the fissure zone was $69.63 \mathrm{MPa}$, and the permeability coefficient was $262.39 \times 10^{-10}$; the ultimate strength of the mudstone in the fissure zone was $28.81 \mathrm{MPa}$, and the permeability coefficient was $0.47 \times 10^{-10}$; the ultimate strength of the sandstone in the intact coal seam floor was $89.63 \mathrm{MPa}$, and the permeability coefficient was $27.90 \times 10^{-10}$; the ultimate strength of the mudstone in the intact coal seam floor was $48.01 \mathrm{MPa}$, and the permeability coefficient was $4.9 \times 10^{-10}$.

The experimental results showed that the ultimate strength of the sandstone in the intact coal seam floor was greater than that of the fissure zone, which was in turn greater than that of the collapsed column; the ultimate strength of the mudstone in the intact coal seam floor was equivalent to that of the collapsed column, which was greater than that of the sandstone in the fissure zone. In terms of the permeability coefficient, the permeability coefficient of the sandstone in the fissure zone was much larger than that in other regions. According to the gradation for rock and earth in the National Standard GB 50487-2008 "Code for Engineering Geological Investigation of Water Resources and Hydropower," [34] the permeability coefficient of sandstone in the fissure zone has reached the "slightly permeable" level, as shown in Table 3.

The fact that the permeability coefficient of the mudstone in the fissure zone around the collapsed column was small, and even smaller than the permeability coefficient of the sandstone in the floor, indicates two problems. (1) The fissure zone around the collapsed column was the main water-permeating channel, while the collapsed column with relatively high compaction and cementation was impermeable in normal conditions. (2) The permeability of the fissure zone around the collapsed column was related to the lithological characteristics of the rock constituting the fissure zone and the sequencing of rock strata. When the lithological characteristics include complete water-resistance or the aquiclude lay under the hard rock stratum, forming a floor of "rigid upper layer and soft lower layer," the damage of mining would have a shallow depth, and the height of the confined water permeation was low, which is the most favorable condition for coal mining above confined water. On-site detection showed that there was water seepage from the collapsed
TABle 3: Permeability gradation for rock and earth.

\begin{tabular}{|c|c|c|c|}
\hline \multirow[b]{2}{*}{$\begin{array}{l}\text { Grade of } \\
\text { permeability }\end{array}$} & \multicolumn{2}{|c|}{ Standard } & \multirow[b]{2}{*}{ Soil type } \\
\hline & $\begin{array}{l}\text { Permeability } \\
\text { coefficient } K \\
(\mathrm{~m} / \mathrm{s})\end{array}$ & $\begin{array}{l}\text { Permeability } \\
q(\mathrm{Lu})\end{array}$ & \\
\hline $\begin{array}{l}\text { Mostly } \\
\text { impermeable }\end{array}$ & $K<10^{-8}$ & $q<0.1$ & Clay \\
\hline $\begin{array}{l}\text { Slightly } \\
\text { permeable }\end{array}$ & $10^{-8} \leq K<10^{-7}$ & $0.1 \leq q<1$ & Clay-silt \\
\hline $\begin{array}{l}\text { Weakly } \\
\text { permeable }\end{array}$ & $10^{-7} \leq K<10^{-6}$ & $1 \leq q<10$ & Silt-fine sand \\
\hline $\begin{array}{l}\text { Moderately } \\
\text { permeable }\end{array}$ & $10^{-6} \leq K<10^{-4}$ & $10 \leq q<100$ & $\begin{array}{l}\text { Sand-sand } \\
\text { gravel }\end{array}$ \\
\hline $\begin{array}{l}\text { Strongly } \\
\text { permeable }\end{array}$ & $10^{-4} \leq K<10^{-2}$ & $q \geq 100$ & $\begin{array}{c}\text { Sand gravel- } \\
\text { gravel }\end{array}$ \\
\hline $\begin{array}{l}\text { Very strongly } \\
\text { permeable }\end{array}$ & $K \geq 10^{-2}$ & & Boulder \\
\hline
\end{tabular}

column and a small amount of water seepage and moisture in the surrounding fissure zone, which was consistent with the analysis results.

\section{Conclusion}

In this study, the disaster-causing mechanism of column collapse was studied. Based on the system theory, a collapsed column is divided into the column and the surrounding fissure zone as two subsystems for analysis. The experiment showed that the average ultimate strength of the collapsed column was approximately $50 \mathrm{MPa}$ and the average peak value of the permeability coefficient was $0.85 \times 10^{-10} \mathrm{~m} / \mathrm{s}$; the ultimate strength of the sandstone fissure zone was $69.63 \mathrm{MPa}$, and the peak value of the permeability coefficient was $262.39 \times 10^{-10} \mathrm{~m} / \mathrm{s}$; the ultimate strength of the mudstone fissure zone was $28.81 \mathrm{MPa}$, and the peak value of the permeability coefficient was $0.47 \times 10^{-10} \mathrm{~m} / \mathrm{s}$, which proved that the fissure zone of the collapsed column was the main water-conducting channel and that the collapsed column had a relatively good degree of compaction and did not allow for water flowing under normal circumstances. The permeability coefficient of the broken rock under different conditions was measured by a self-designed equipment. The variations of the permeability coefficient for rock samples with different particle diameters, different axial pressures $P_{\mathrm{a}}$ and different seepage velocities were further studied. Through phenomena analysis and experimental data processing, it was 
concluded that, under the same pressure state, smaller particle diameter meant smaller permeability coefficient; with the increase of axial pressure, the permeability coefficient decreased; and the larger the water flow velocity was, the smaller the permeability coefficient became. For particle diameter $\Phi=2.5-5 \mathrm{~mm}$ or larger, the tiny particles formed by randomly washing and breaking in the water flow blocked some of the channels. For particle diameters smaller than $\Phi=2.5-5 \mathrm{~mm}$, the smaller permeability coefficient was attributed to the turbulence resulting from non-Darcy flow. The study on the permeability of the fractured rock mass clarified the mechanism of water inrush from the fissure zone of the collapsed column: the collapsed column itself was impermeable, and the permeability of the fissure zone around the collapsed column was related to the lithological characteristics of the rock within the fissure zone and the sequencing of rock strata. When mining coal in areas with collapsed columns, experiments on collapsed columns and fissure zone-s are prerequisites. This study has certain referential value for coal mining in this region.

\section{Data Availability}

The data used to support the findings of this study are available from the corresponding author upon request.

\section{Conflicts of Interest}

The authors declare that there are no conflicts of interest regarding the publication of this paper.

\section{Acknowledgments}

The authors also gratefully acknowledge the financial support of the National Key Research and Development Program (Grant no. 2016YFC0501102), Open Fund of State Key Laboratory of Water Resource Protection and Utilization in Coal Mining (Grant no. SHJT-17-42.5), and Open Fund of State Key Laboratory of Coal Resources and Safe Mining (Grant no. SKLCRSM17KFB04).

\section{References}

[1] W. Sun, W. Zhou, and J. Jiao, "Hydrogeological classification and water inrush accidents in China's coal mines," Mine Water and the Environment, vol. 35, no. 2, pp. 214-220, 2016.

[2] T. I. Williams, "China statistical yearbook 1994," Endeavour, vol. 19, no. 4, p. 172, 1995.

[3] L. P. Li, Z. Q. Zhou, S. C. Li et al., "An attribute synthetic evaluation system for risk assessment of floor water inrush in coal mines," Mine Water and the Environment, vol. 34, no. 3, pp. 288-294, 2014.

[4] Q. Wu, Y. Liu, L. Luo et al., "Quantitative evaluation and prediction of water inrush vulnerability from aquifers overlying coal seams in Donghuantuo Coal Mine, China," Environmental Earth Sciences, vol. 74, no. 2, pp. 1429-1437, 2015.
[5] L. Thomas, Coal Geology, John Wiley \& Sons, Hoboken, NJ, USA, 2002.

[6] H. Zhang, X. L. Jin, L. I. Gui-Hong et al., "Comparison of coalfields and coal-mining geological conditions of the main coal-producing countries in the world," Coal Geology and Exploration, vol. 35, no. 6, pp. 1-9, 2007.

[7] A. C. Cook, "Australian black coal: its occurrence, mining, preparation, and use," in Proceedings of Symposium on Australian Black Coal, its Occurrence, Mining, Preparation, and Use, University of Wollongong, Wollongong, NSW, Australia, 1975.

[8] T. Sarkus and W. Ellis, "Coal resources, production, and use worldwide," in Fossil Fuels: Current Status and Future Directions, pp. 1-22, World Scientific, Singapore, 2016.

[9] S. Dai and R. B. Finkelman, "Coal geology in China: an overview," International Geology Review, vol. 60, no. 5-6, pp. 531-534, 2017.

[10] A. P. Chikkatur, "Making the best use of India's coal resources," Economic \& Political Weekly, vol. 40, no. 52, pp. 5457-5461, 2005.

[11] Y.S. Xian and W. U. Qiang, "Hydrogeological and mechanical basics of water inrush from karstic collapse columns in Northern China," Journal of China Coal Society, vol. 29, no. 2, pp. 182-185, 2004.

[12] K. Q. He, G. M. Yu, and Y. R. Lu, "Palaeo-karst collapse pillars in northern China and their damage to the geological environments," Environmental Geology, vol. 58, no. 5, pp. 10291040, 2009.

[13] K. He, G. Dong, D. Wen et al., "The effects of karst collapse on the environments in north China," Environmental Geology, vol. 52, no. 3, pp. 449-455, 2007.

[14] B. Yao, X. Mao, J. Wei et al., "Study on coupled fluid-solid model for collapse columns considering the effect of particle transport," Journal of China University of Mining and Technology, vol. 43, no. 1, pp. 30-35, 2014.

[15] X. Qian, "The formation of gypsum karst collapse-collum and its hydrogeological significance," Carsologica Sinica, vol. 7, no. 4, pp. 344-348, 1988.

[16] B. Yu, Z. Chen, and L. Yu, "Water-resisting ability of cemented broken rocks," International Journal of Mining Science and Technology, vol. 26, no. 3, pp. 449-454, 2016.

[17] H. Liu, L. Li, Z. Li et al., "Numerical modelling of mininginduced inrushes from subjacent water conducting karst collapse columns in Northern China," Mine Water and the Environment, vol. 1, pp. 1-11, 2017.

[18] B. Zhang, H. Bai, and K. Zhang, "Seepage characteristics of collapse column fillings," International Journal of Mining Science and Technology, vol. 26, no. 2, pp. 333-338, 2016.

[19] D. Ma and H. Bai, "Groundwater inflow prediction model of karst collapse pillar: a case study for mining-induced groundwater inrush risk," Natural Hazards, vol. 76, no. 2, pp. 1319-1334, 2015.

[20] L. Wang, Z. Chen, H. Kong et al., "An experimental study of the influence of seepage pressure and initial porosity on variable mass seepage for broken mudstone," Journal of Mining and Safety Engineering, vol. 31, no. 3, pp. 462-468, 2014.

[21] D. Ma, H. Bai, Z. Chen et al., "Effect of particle mixture on seepage properties of crushed mudstones," Transport in Porous Media, vol. 108, no. 2, pp. 257-277, 2015.

[22] F. Gong, L. I. Xibing, X. Liu et al., "Experimental study of dynamic characteristics of sandstone under one-dimensional coupled static and dynamic loads," Chinese Journal of Rock Mechanics and Engineering, vol. 29, no. 10, pp. 2076-2085, 2010. 
[23] Y. Zhang, X. U. Hong, L. I. Ping et al., "Experimental study on seepage properties of fractured maokou limestone," Mining Safety \& Environmental Protection, vol. 43, no. 1, pp. 12-16, 2016.

[24] W. Wan, Y. Zhao, J. Tang et al., "Experimental study on hydraulic properties of fractured Maokou limestone," Mineral Engineering Research, vol. 31, no. 3, pp. 1-7, 2016.

[25] D. Ma, H. Bai, and Y. Wang, "Mechanical behavior of a coal seam penetrated by a karst collapse pillar: mining-induced groundwater inrush risk," Natural Hazards, vol. 75, no. 3, pp. 2137-2151, 2015.

[26] Z. Li, H. Xie, J. Li et al., "Experimental study of mining effect on collapse column activated water conducting mechanism," Journal of Central South University, vol. 45, no. 12, pp. 4377-4383, 2014.

[27] J. Wang and F. Gong, "Study on rate effect of uniaxial compression test for red sandstone," Gold Science \& Technology, vol. 26, no. 1, pp. 56-63, 2018.

[28] P. Liu, C. Feng, F. Wang et al., "Hydrophobic and waterresisting behavior of Portland cement incorporated by oleic acid modified fly ash," Materials and Structures, vol. 51, no. 2, p. 38, 2018.

[29] D. Ma, X. X. Miao, Z. Q. Chen et al., "Erratum to: experimental investigation of seepage properties of fractured rocks under different confining pressures," Rock Mechanics and Rock Engineering, vol. 48, no. 5, p. 2183, 2015.

[30] P. Liu, Y. Gao, F. Wang et al., "Superhydrophobic and selfcleaning behavior of Portland cement with lotus-leaf-like microstructure," Journal of Cleaner Production, vol. 156, pp. 775-785, 2017.

[31] C. Jiang, M. Duan, G. Yin et al., "Experimental study on seepage properties, AE characteristics and energy dissipation of coal under tiered cyclic loading," Engineering Geology, vol. 221, pp. 114-123, 2017.

[32] P. F. Germann, "Viscosity-the weak link between Darcy's law and Richards' capillary flow," Hydrological Processes, vol. 32, no. 9, pp. 1166-1172, 2018.

[33] X. Chen, B. Zeng, C. Wang et al., "A study of the equivalent hydraulic conductivity of layered heterogeneous media with the particle flow theory," Hydrogeology and Engineering Geology, vol. 45, no. 2, pp. 7-12, 2018.

[34] N. C. Matalas and C. F. Nordin, "Water resources of the People's Republic of China," Eos Transactions American Geophysical Union, vol. 61, no. 46, pp. 891-901, 2013. 


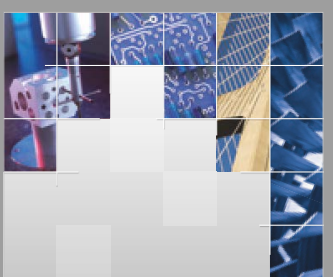

\section{Enfincering}
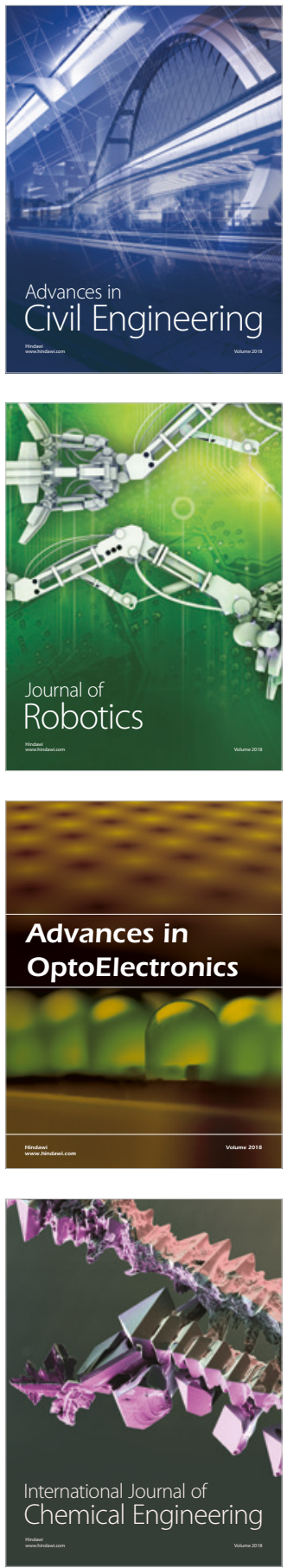

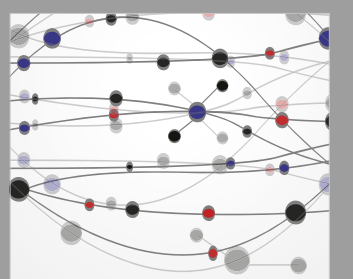

\section{Rotating \\ Machinery}

The Scientific World Journal

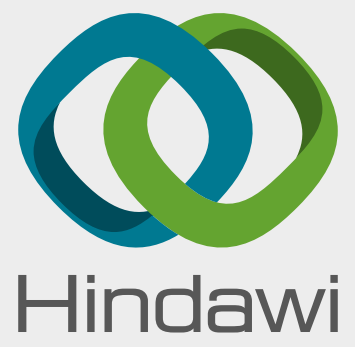

Submit your manuscripts at

www.hindawi.com
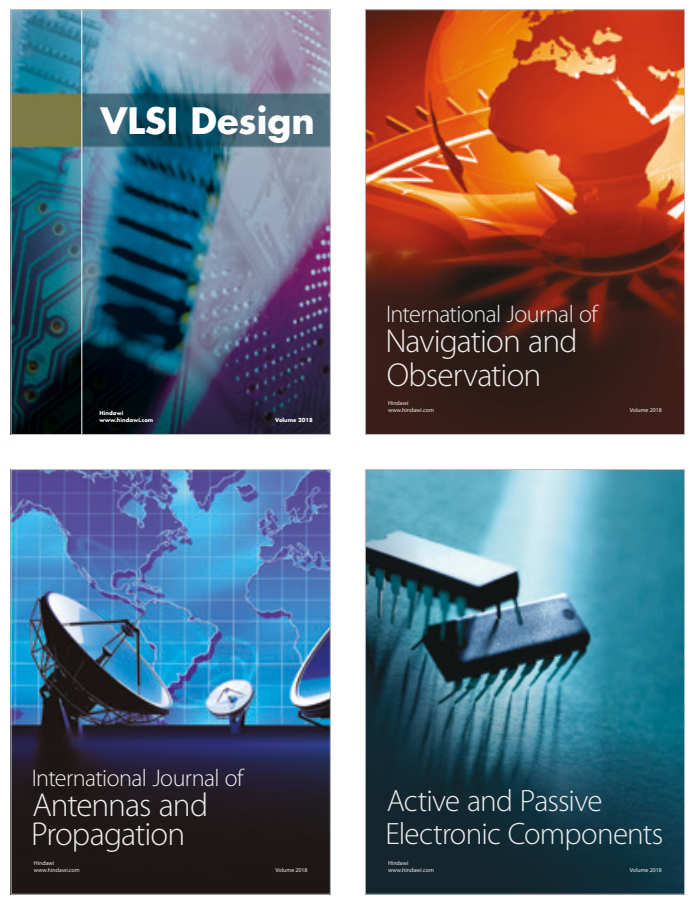
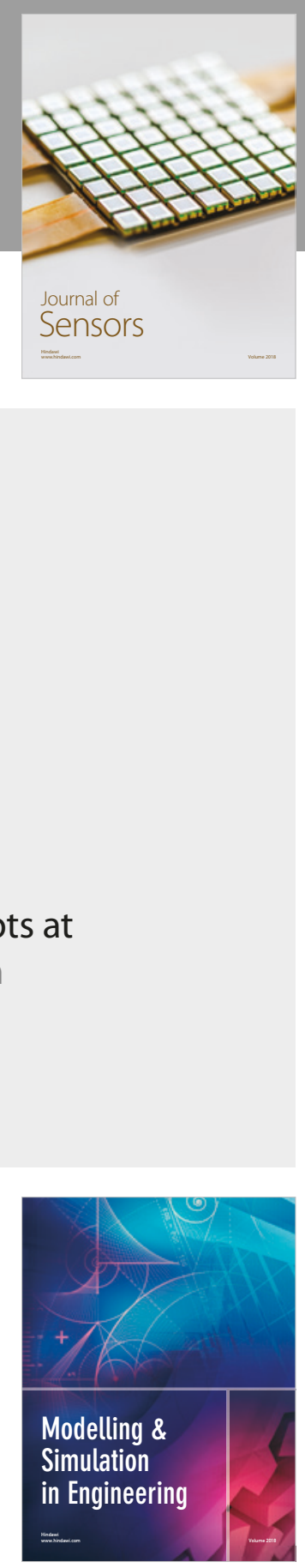

\section{Advances \\ Multimedia}
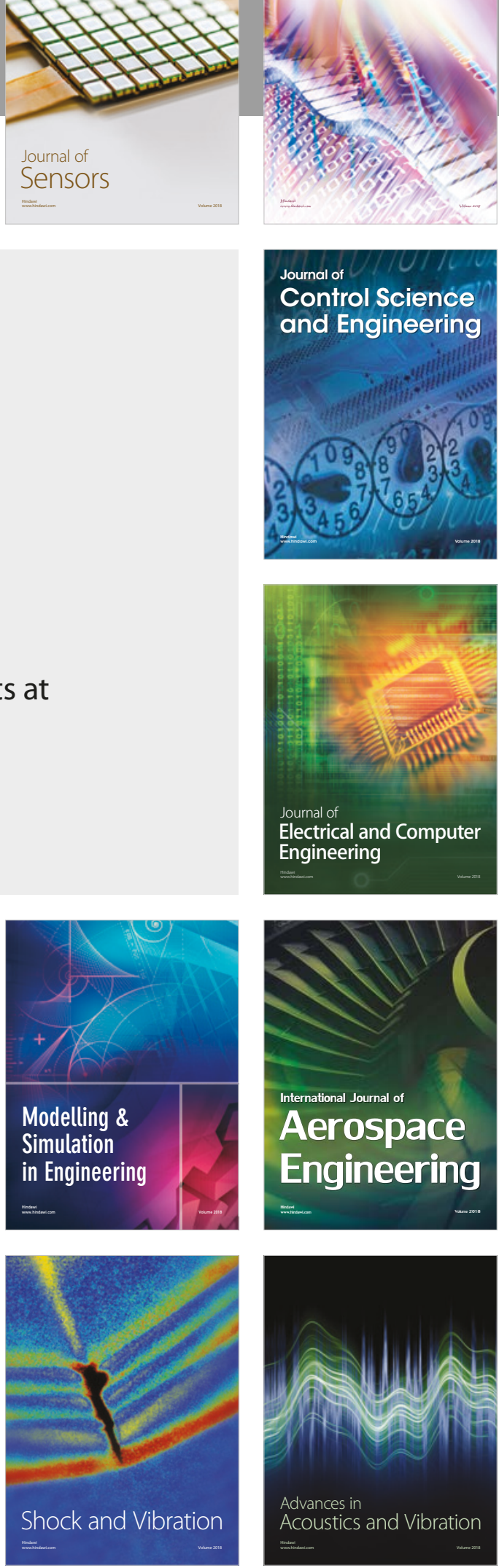